\title{
Evaluation of Physicochemical and Antioxidant Properties of Pinus gerardiana Nuts and Oil
}

\author{
Mahdiyeh Sheikhahmadi, Mohammad A Sahari*, Mohsen Barzegar \\ Department of Food Science and Technology, Faculty of Agriculture, Tarbiat Modares University, Tehran, Iran \\ E-mail: sahari@modares.ac.ir (Corresponding author).
}

Received: 21 March 2020; Accepted: 3 April 2020; Available online: 30 May 2020

\begin{abstract}
For optimal usage of new oil resources with high nutritional values, in this study, one chilgoza pine variety was provided, and assays of physicochemical characteristics of its nut such as moisture, ash, thousand nut weight, oil, protein, hull contents, density, $\mathrm{pH}$ and also physicochemical characteristics of its extracted oil by nhexan solvent such as iodine values, saponification and unsaponification, peroxide, specific weight, acid values, moisture of oil, color (Lovibond) and fatty acid profile and extracted oil characteristics by cold press such as total polyphenols, tocophrols, carotenoids, chlorophylls, sterols, color (Hunterlab), DPP $\dot{H}$ and antioxidant were investigated. Then its effect as a natural antioxidant on rapeseed oil shelf life (without any antioxidant) was studied. The results indicated that chilgoza pine oil is belonged to linoleic-oleic group. Oil of chilgoza pine has $\alpha$ and $\gamma$ tocopherols and there is no $\beta$ and $\delta$ tocopherols on it. The oil of chilgoza pine, were mixed at two levels of $2 \%$ and $5 \%$ with rapeseed oil and these mixed were determined by peroxide, TBA and Rancimat indices during $0,5,10$, 20 and 35 days and compared with control. Statistical results showed no antioxidant effect in shelf life of rapeseed oil at more days. This means that the chilgoza pine oil antioxidant compounds were not enough to prevent oxidative rancidity of rapeseed oil or maybe the antioxidant compounds of nuts were not migrated to oil.
\end{abstract}

Keywords: Chilgoza pine oil; Physicochemical characteristics; Antioxidant assays; Rapeseed oil.

\section{Introduction}

Edible nut of the chilgoza pine plant is called chilgoza pine nut (Pinus gerardiana W. ex D.), which belong to the Pinaceae family. The first places were observed were near Pakistan, India, Afghanistan and China [1]. For first time it was discovered by Captain Gerard in the year of 1932 and commercially known as chilgoza/neoza pine [2]. The species have different calls in some areas such as Jhalgoza in Afghanistan, Chiri or Chilgoza in Kashmir, Rhi or Neoza in Kinnaur, Chujin in Chitral and Mirri in Pangi (Himachal Pradesh). They grow between 1,600 and 3,300 $\mathrm{m}$ above sea level and are abundant in Himachal Pradesh (a total area of about 2,060 ha) and most of the area in Kinnaur (2,040 ha) and a small portion in Chamba district (20 ha). These species can grow under extremely rough site condition and because of the withstand the extremes of cold climate and also aridity, they were described as the "Champion of Rocky Mountains"' [3].

Reduction in the regeneration process in the natural habitats of chigoza pine tree is due to the rare and irregular years of the nuts. Chilgoza pine is a rich source of turpentine resins. Its nuts and oils have therapeutic properties; its nuts are useful to improve ulcers and stomach ulcers as they are as anodyne and stimulant and their oils are useful to improve ulcers and stomach ulcers. [3]. Also, the oil of this nut has a hypo-liposomal effect and lower blood cholesterol, and even has the potential to limit appetite and treatment for obesity [4].

Chilgoza pine is known as one of the important internationals commercially goods. It used as roasted nut or as an ingredient in desserts, sauces and salads [1]. Its kernels are rich in fats, proteins and carbohydrates with no cholesterol [5] and also rich in unsaturated fatty acids (especially polyunsaturated fatty acids), which have health benefits such as controlling the blood serum lipid profile (notably the decrease in undesirable low-density cholesterols, very low density lipoproteins and low density lipoproteins) [6].

Chilgoza pine nuts have been considered as an important source of plant proteins. The protein is a well-balanced composition of essential amino acids and is rich in arginine, which is related to many types of bioactivities, including antioxidant, vasodilatation and antiplatelet effects. It also contains a high amount of lysine, therefore these are useful to improve the essential amino acid content in grain-based diets [1].

In general, pine nuts contain approximately 50\% fat, 30\% proteins, $10 \%$ carbohydrate, $4 \%$ ash and $6 \%$ moisture. They are also rich in unsaturated fatty acids (UFAs). A previous study on a species of pine nuts, reported $51 \%$ linoleic acid, and 37\% oleic acid, which were known to contain the highest levels of UFAs [7]. Pine nuts contain 
high amounts of fats and unsaturated fatty acids, therefore they are prone to hydrophilic and oxidative rancidity, which leads to spoilage during storage [6].

The above contents indicate the importance of chilgoza pine nut and its oil in nutrition and also as a medicine in the treatment of named diseases. In Iran, no similar study has been done on this nut and its physicochemical characteristics and it has been paid very little attention on the global level. Therefore, in this research, the physicochemical characteristics of this oil and nut, as well as the study of the number of effective compounds, their classification to the oleic or linoleic acid group and the mode of antioxidant activity of the oil were investigated.

\section{Materials and methods}

Chilgoza pine nuts used in this study were supplied from a local market of Mashhad. All reagents used were of analytical grade and were obtained from Merck, Company (Darmstadt, Germany).

\subsection{Preparing samples}

At first, all the nuts were peeled off and their nuts were separated. Then, physicochemical tests were performed on its nuts. To determine the physicochemical properties of the oil, two types of methods were used as follow.

\subsection{Analysis of chilgoza pine nut samples}

The nuts were ground by using a mortar and pestle. Then moisture content, ash value, protein content, thousand nut weight, oil, protein, hull contents, density and $\mathrm{pH}$ also were determined according to AOCS methods [8].

\subsection{Analysis of chilgoza pine nut oil}

Physicochemical characteristics of chilgoza nut oil extracted by n-hexane solvent under vacuum at $55-60{ }^{\circ} \mathrm{C}$, such as iodine (Hanus method), unsaponification [9], acidity, saponification, peroxide, TBA and Rancimat values refractive index [8] color (Lovibond) [10] were determined. Also, for investigation of oil antioxidant assays, chilgoza pine nut oil was extracted by cold press equipment (Bekrdaneh BDE65, Iran); Then physicochemical characteristics of chilgoza nut oil, such as total polyphenols [11], carotenoids and chlorophylls [10], color (Hunter lab) [10] contents, DPPH [12] and antioxidant activities were determined [13] and sterols and tocopherols were measured according to INSO 16324 [14] and INSO 7211 [15], respectively.

\subsection{Analysis of fatty acid composition}

In order to estimating fatty acid composition, which was done by gas chromatography (Unicom 4600, England), extracted oil by n-hexane solvent was used. Split injection, split ratio 1:10, injection temperature at $250{ }^{\circ} \mathrm{C}$, flame ionization detector at $300{ }^{\circ} \mathrm{C}$ and Helium with $99.99 \%$ purity and $1 \mathrm{ml} / \mathrm{min}$ flow rate as carrier gas were device specifications. Fatty acid composition was determined through a fused silica capillary column (BPX70; SGE, Melbourne, Australia) $30 \mathrm{~m} \times 0.22 \mathrm{~mm}$ with the film thickness of $0.25 \mu \mathrm{m}$. Initial column temperature was 110 ${ }^{\circ} \mathrm{C}$ for 5 minutes and was increased to $210^{\circ} \mathrm{C}$ at the rate of $5{ }^{\circ} \mathrm{C} / \mathrm{min}$, and held at this temperature for 40 minutes [16].

\subsection{Analysis of sterols contents}

Sterol compositions were determined by gas chromatography (Young Lin Acme 6000, South Korea). Split injection, split ratio 1:50, injection temperature at $280^{\circ} \mathrm{C}$, flame ionization detector at $300^{\circ} \mathrm{C}$ and hydrogen with $1 \mathrm{ml} / \mathrm{min}$ flow rate as carrier gas were device specifications. Sterol compositions were determined through a Supelco/Equity-5 column (30 m $\times 0.25 \mathrm{~mm}$ ID, $0.25 \mathrm{~mm}$ film thickness). Initial column temperature was $260{ }^{\circ} \mathrm{C}$ for 30 minutes and was increased to $290{ }^{\circ} \mathrm{C}$ at the rate of $10{ }^{\circ} \mathrm{C} / \mathrm{min}$, and held at this temperature for 20 minutes (INSO 16324) [14].

\subsection{Analysis of tocopherols content}

Tocopherols were analyzed by high performance liquid chromatography (HPLC, Younglin, South Korea) with SP930D pump and equipped with the ultraviolet detector (UV730D), manual injection system with the loop $20 \mu 1$ and Autochrome 3000 software. Tocopherols were separated on a $\mathrm{C}_{18}$ column $(25 \mathrm{~cm} \times 4.6 \mathrm{~mm}$ ID, $5 \mathrm{~mm}$ particle size). Mobile phase of methanol and acetonitrile (for determination of tocopherol compounds) and flow rate of 1 $\mathrm{ml} / \mathrm{min}$ at $30^{\circ} \mathrm{C}$ and $20 \mu \mathrm{L}$ injection volume were used [15].

\subsection{Statistical analysis}


Each of the experiments was performed in three replications. SPSS software and one-way ANOVA were used to determine the significance or absence of differences between the test values and the antioxidant effect of chilgoza pine nut oil. For the difference between treatments and total factors, LSD output test was used.

\section{Results and discussion}

\subsection{Composition of chilgoza pine nuts}

The average of physicochemical characteristics of dried chilgoza pine nuts are presented in Table 1 . The average hull content was $44.93 \%$. The average moisture content was $2.84 \%$, which shows that the nuts could be stored for a long time than previous research on dried chilgoza pine of Kinnaur region with higher moisture content (6.8\%) [5] which could due to decomposition of fatty acids due to microbial activities and decrease in the storage time. On the other hand, the difference could be resulted of the items such as variety, location, climate zone and so on.

The nuts had approximately $2.86 \%$ ash content, which is near to the count of dried chilgoza pine nuts of Kinnaur region $(2.7 \%)$ and they are due to the soil composition of Kinnaur in absorb minerals by plant. The nut average protein content was $20.82 \%$, which is higher than previous study has been reported to be $12 \%$ [5].

The average nut oil content was $48.78 \%$ which is virtually the same with previous study has been reported to be $49.4 \%$ [5]. The average $\mathrm{pH}$ of nuts was 6.67 . According to the researches in this field, no similar studies have been carried out. This test indicated the state of oxidative degradation of unsaturated fatty acids associated with the seedling. According to studies that are not the subject of this research, these nuts are sensitive to fusarium growth and germination, thus, this test can partially measure the states of corruption. Normally, this number for wheat flour is about 6.1 - 6.2 and, as can be seen, the $\mathrm{pH}$ of the chilgoza pine nut is close to this number; hence, if the nuts are corrosive, the $\mathrm{pH}$ number it will diminish.

Another measured item was such as thousand nut weight $(259.71 \mathrm{~g})$ and density $\left(1.10 \mathrm{~kg} / \mathrm{m}^{3}\right)$. There were not any similar researches in this case to compare.

The present sample has heavy metals such as iron $(0.01 \mathrm{mg} / \mathrm{kg})$, copper $(0.04 \mathrm{~m} / \mathrm{kg})$, lead (0.01 mg/kg) and no arsenic metal.

Table 1. Physicochemical characteristics of chilgoza pine nuts and compare it to some edible seeds

\begin{tabular}{llll}
\hline Characteristics & Present study & Chilgoza nut [5] & Other studies \\
\hline Hull (\%) & $44.93 \pm 6.08$ & - & $21-35$ (Sunflower seed) [17] \\
Moisture (\%) & $2.84 \pm 0.03$ & 6.8 & 12 (Sunflower seed) [17] \\
Ash (\%) & $2.86 \pm 0.13$ & 4 & 5 (Soy bean) [17] \\
Protein (\%) & $20.82 \pm 0.23$ & 12 & $6-12$ (Corn seed) [17] \\
Oil (\%) & $48.78 \pm 0.23$ & 49.4 & 45.09 (Peanut; Golden) [18] \\
Thousand nut weight (g) & $259.71 \pm 11.58$ & - & 5.10 (Rapeseed) [19] \\
pH & $6.67 \pm 0.01$ & - & - \\
Density (kg/cm $\left.{ }^{3}\right)$ & $1.10 \pm 0.03$ & - & $1.12-1.21$ (Soy bean) [20] \\
\hline Heavy metals (ppm) & & & - \\
Cu & $0.04 \pm 0.00$ & - & 0.1 (Sesame seed) [21] \\
Pb & $0.01 \pm 0.00$ & - & 0.1 (Sesame seed) [21] \\
As & ND & - & - \\
Fe & $0.01 \pm 0.00$ & - & \\
$* \mathrm{ND}=$ didn't detect. Data are based on mean values of three independent replicate \pm SD.
\end{tabular}

* ND= didn't detect. Data are based on mean values of three independent replicate \pm SD.

\subsection{Composition of chilgoza pine nut oil extracted by n-hexan}

Iodine, saponification and unsaponifiable, refractive indexes, acid, peroxide, specific gravity values, moisture content, color and oxidative stability of oil samples extracted from chilgoza pine oil extracted by n-hexane are shown in Table 2. Iodine value determines unsaturation degree in the oil samples. This value for food product is between 75 and $150 \mathrm{~g}[15,20]$. The iodine value was $121.9 \mathrm{~g}$, which are near to the reported count in previous study [22]. The iodine value, in this case, indicates that the number of unsaturated fatty acids in the chilgoza pine oil is high and this is evident from the amount of acid and free fatty acids values. Saponification value, which is measurement of the average molecular weight of the constituent fatty acids in the lipid, was $97.79 \mathrm{mg} \mathrm{KOH} / \mathrm{g}$ for chilgoza pine nut oil. This count shows a high different to previous study (295 g) which is due to the length of fatty acid chain, that contained of 51.64\% PUFA and thus decrease of saponification value. The unsaponifiable value is almost used for Fraud detection. It was $1.61 \%$ for present sample and lower than previous study (5.5 weight percent) [22]. The refractive index is important to determine the type and purity of the oil. The average of sample's refractive index in $20^{\circ} \mathrm{C}$ was 1.4739 , which was near to the count measured in previous study about 1.4692 [22]. The acid value was 0.49 (mg KOH/g oil), which was so lower than previous study (4 mg KOH/g oil) 
[22]. As reported before, the maximum value of acidity accepted for oil used as food product is $0.6 \%$ and oil sample shows a good acidity range.

In general, peroxide is the primary product of oxidation of fatty substances, and as a whole, the higher degree of non-saturation of oils, the oil or the fatty substance is more readily oxidized, and peroxide represents the degree of oxidation progression. The average sample's peroxide value was 6.59 (meq O$/ 2 / \mathrm{kg}$ oil).

Specific gravity is not the same for all oils and depends on the composition of fatty acids, low-amount compounds in the oil and also the temperature. The average of specific gravity of the sample is $0.9167 \mathrm{~g} / \mathrm{cm}^{3}$. This number is similar to the values of oil in previous study with an average value of $0.9187 \mathrm{~g} / \mathrm{cm}^{3}$ [22].

The amount of moisture in the chilgoza pine nut oil is an average of $0.0003 \%$. Due to the lower amount of moisture of the nuts and its content of the oil, this oil is expected to have a good resistance to degradation and storage conditions.

The intensity of the color measure by the Lovibond device this oil is an average of yellow: -23.33 and red: 2.25. The color was lower compared to sunflower oil (45 yellow and 2 red) and the oil of wild horseradish of the Pakistani region (31 yellow and 1.28 red) [23].

The average of stability time for the present sample was 15.18 hours. This number is higher than the resistance ranges of safflower oil (9-12 hours) [17] and the oil of wild horseradish of the Pakistani region (8.40 hours) [23]. It's also close to the minimum amount of soybean oil (15 hours) [24]. The average of heavy metals of this oil such as $\mathrm{Cu}, \mathrm{Pb}, \mathrm{Fe}$ were, respectively, 0.05, 0.01, $0.54 \mathrm{ppm}$. There were not detected any as element in this sample. This oil has no cadmium in comparison to corn oil $(0.2 \mathrm{mg} / \mathrm{kg})$ [25] and has a lower lead content and compared with sunflower oil has lower Iron (up to $4.4 \mathrm{mg} / \mathrm{kg}$ ) and copper (up to $3.1 \mathrm{mg} / \mathrm{kg}$ ) [26].

Table 2. Physicochemical composition of chilgoza pine nut oil extracted by n-hexane

\begin{tabular}{ll}
\hline Characteristics & Amount \\
\hline Iodin value $(\mathrm{GC})(\mathrm{g})$ & $124.24 \pm 0.43$ \\
Iodin value (Hanus) $(\mathrm{g})$ & $121.9 \pm 0.16$ \\
Saponification value $(\mathrm{mg} \mathrm{KOH} / \mathrm{g})$ & $97.79 \pm 0.23$ \\
Unsaponifiable value $(\%)$ & $1.61 \pm 0.09$ \\
Refractive index (analog) $\left(20^{\circ} \mathrm{C}\right)$ & $1.4739 \pm 0.0001$ \\
Refractive index $($ digital $)\left(20^{\circ} \mathrm{C}\right)$ & $1.4661 \pm 0.0004$ \\
Acid value $(\mathrm{mg} \mathrm{KOH} / \mathrm{g}$ oil $)$ & $0.49 \pm 0.05$ \\
Peroxide value $(\mathrm{mEq} \mathrm{O} / \mathrm{kg}$ oil) & $6.59 \pm 0.34$ \\
Specific gravity $\left(\mathrm{g} / \mathrm{cm}^{3}\right)$ & $0.9167 \pm 0.43$ \\
Rancimat $(\mathrm{h})$ & $15.18 \pm 0.32$ \\
Moisture content $(\%)$ & $0.0003 \pm 0.0003$ \\
\hline Color & \\
red & $2.25 \pm 0.057$ \\
yellow & $-23.33 \pm 0.57$ \\
\hline Heavy metals $(\mathrm{mg} / \mathrm{kg})$ & \\
$\mathrm{Cu}$ & $0.05 \pm 0.00$ \\
$\mathrm{~Pb}$ & $0.01 \pm 0.00$ \\
Fe & $0.54 \pm 0.01$ \\
As & $\mathrm{ND}$ \\
\hline *ND didn't detect. Data are based on mean values of three independent replicate $\pm \mathrm{SD}$.
\end{tabular}

According to the table 3, this oil is classified as oleic-linoleic group oils. This group is the most abundant and largest category of edible oils, and the oils of this group usually have high unsaturated fatty acids, and their saturated fatty acids are generally less than $20 \%$. Therefore, this oil is a rich source of fatty acids of $\omega 6$ and $\omega 9$ because of its high amounts of linoleic acid (50.75\%) and oleic acid (40.45\%), which are the most important fatty acids. Compared with previous study, the present oil sample has a similar amount of linoleic acid (52.7\%), but less oleic acid (36\%) [22]. The most abundant saturated fatty acid is palmitic acid with an average of 5.62\%. This oil is not a rich source of linolenic fatty acids, and its average is $0.89 \%$.

For measuring the factors such as the amounts of tocopherols, sterols, polyphenols, total carotenoids and chlorophylls of chilgoza pine nut oil, color (Hunterlab), and also the test for determining the antioxidant properties of the oil (Table 4), the chilgoza pine nuts were extracted by cold pressing method. In the cold pressing extraction method, approximately of half of the total weight of the sample, equivalent to $785 \mathrm{~g}$, about $320 \mathrm{~g}$ oil was extracted, which was better than solvent extraction. This is due to the application of a temperature lower than hexane boiling point $\left(55-60^{\circ} \mathrm{C}\right)$ in solvent extraction to prevent the effect of temperature on increasing peroxide values.

The average total sterol of the present sample is about 3,995.41 ppm. The chilgoza pine nut oil is rich in betasitosterol $(69.29 \mathrm{ppm})$ which is the most abundant plant sterol. Compared to that, stigma sterol is very small 
(1.85\%). Campesterol with an average of $20.4 \%$ is the most abundant plant sterol after beta-sitosterol in this oil. The amount of $\Delta 5$-avenasterol, which is the index sterol in sesame oil with high antioxidant properties, is very low in this oil and is about $0.47 \%$. Other sterol compounds are less than $1 \%$ and this oil is free of cholesterol.

Table 3. Fatty acid composition of chilgoza pine nut oil extracted by n-hexane

\begin{tabular}{ll}
\hline Fatty acid composition (\%) & Amount \\
\hline C16:0 & $5.62 \pm 1.33$ \\
C18:0 & $1.74 \pm 0.36$ \\
C18:1 & $40.45 \pm 0.42$ \\
C18:2 & $50.75 \pm 0.85$ \\
C18:3 & $0.89 \pm 0.29$ \\
C20:0 & ND \\
C22:0 & ND \\
$\sum$ SFA & $3.68 \pm 0.23$ \\
$\sum$ MUFA & $40.45 \pm 0.42$ \\
$\sum$ PUFA & $51.64 \pm 0.57$ \\
\hline
\end{tabular}

* ND= didn't detect. Data are based on mean values of three independent replicates \pm SD.

Tocopherols are the most important natural antioxidants and are found in many oils. Tocopherols have both antioxidant and vitaminic properties, and these two properties are unique. In the present study, the most abundant tocopherol of chilgoza pine nut oil is $\gamma$ - tocopherol with an average of $101.51 \mathrm{ppm}$ and followed by the $\alpha$ tocopherol with an average of $7.72 \mathrm{ppm}$, is in the second place. This oil does not contain $\delta$ and $\beta$ - tocopherols. The average polyphenols of chilgoza pine nut oil were $168.44 \mathrm{ppm}$. The amount of these compounds depends on the method of extraction, variety, and so on.

Table 4. Physicochemical composition of chilgoza pine nut oil extracted by cold press

\begin{tabular}{ll}
\hline Characteristics & Amount \\
\hline Sterol composition (\%) & \\
Cholesterol & ND \\
Brasikasterol & $0.01 \pm 0.00$ \\
Campsterol & $20.4 \pm 0.05$ \\
Stigma sterol & $1.85 \pm 0.04$ \\
Betasitosterol & $69.29 \pm 0.1$ \\
Sitostanol & $8.05 \pm 0.09$ \\
$\Delta-5$-avenasterol & $0.47 \pm 0.02$ \\
$\Delta-5$ and 24 stigma esta de enol & $0.27 \pm 0.02$ \\
Total sterol & $3995.41 \pm 35.1$ \\
\hline Tocopherol (ppm) & \\
$\alpha$ & $7.72 \pm 0.16$ \\
$\gamma$ & $101.51 \pm 1.07$ \\
Total carotenoid (ppm) & $1.39 \pm 0.02$ \\
Total chlorophyll (ppm) & $0.087 \pm 0.005$ \\
Total polyphenol (ppm) & $167.26 \pm 1.1$ \\
DPPH (\%) & $57.5 \pm 0.4$ \\
\hline
\end{tabular}

$* \mathrm{ND}=$ didn't detect. Data are based on mean values of three independent replicates \pm SD.

The DPPH test is widely used to test the ability of compounds to act as free radical or hydrogen inhibitors, and it estimates the antioxidant activity of food [27]. The main task of this method is to measure the free radicals created by direct oxidation of the oils. Oxidized oils with a higher content of unsaturated fatty acids (PUFA) than those with lower levels of this type of fatty acid have a larger effect on the absorption of DPPH or the formation of free radicals and therefore are more sensitive to oxidation. Tocopherols play a major role in the determination of antioxidant properties in refined vegetable oils, and in contrast, other antioxidants, such as polyphenols and carotenoids, are removed or degraded during the refining process [28]. As a result, it is expected that in chilgoza pine nut oil obtained by cold pressing method, the most important factor in determining its antioxidant properties is the amount of polyphenols and their type. Antioxidant activity (EC50) (50\% reduction in initial DPPH radical absorbance) of chilgoza pine nut oil is $57.5 \%$ (100 ppm of the sample).

The amount of total carotenoids in the chilgoza pine nut oil is $1.39 \mathrm{ppm}$ and the total chlorophyll content is $0.087 \mathrm{ppm}$. In a previous study, the amounts of $\beta$-carotene in some types of oil extracted by cold pressing method 
was measured. Also the counts of $\beta$-carotene were measured in the oils extracted by the solvent. It was observed that $\beta$ - carotene just only is found in the cold pressed oils; hence, chilgoza pine nut oil is likely to contain $\beta$ carotene, because it was prepared by cold pressing method.

The intensity of the color of chilgoza pine nut oil by cold pressing method was according as follow:

$a^{*}:-3.02 ; L^{*}: 56.28 ; b^{*}: 49.28$

Some physicochemical composition of chilgoza pine nut oil was compared with other oils (Table 5-6).

Table 5. Physicochemical composition of chilgoza pine nut oil extracted by n-hexane compare to other oils

\begin{tabular}{|c|c|c|}
\hline Characteristics & Present study & Other studies \\
\hline Iodin value (Hanus) (g) & 121.9 & $\begin{array}{l}145 \text { (American safflower oil) [17] } \\
112.1 \text { (Canola oil) [29] } \\
114.3 \text { (Cashew) [30] }\end{array}$ \\
\hline Saponification value (mg KOH/g) & 97.79 & $\begin{array}{l}224.40 \text { (Peanut oil; Bari 2000) [18] } \\
\text { 186-194 (Edible safflower oil) [31] }\end{array}$ \\
\hline Unsaponifiable value (\%) & 1.61 & $\begin{array}{l}4 \text { (Peanut oil (Mungphalla)) [18] } \\
2.8 \text { (Corn oil) [17] } \\
1.5 \text { (Extra virgin olive oil) [32] }\end{array}$ \\
\hline Refractive index (analog) $\left(20^{\circ} \mathrm{C}\right)$ & 1.4739 & $\begin{array}{l}1.4571 \text { (Moringa oleifera seeds oil) [33] } \\
1.4745 \text { (American safflower oil) [17] }\end{array}$ \\
\hline $\begin{array}{l}\text { Acid value } \\
\text { (mg KOH/g oil) }\end{array}$ & 0.49 & $\begin{array}{l}12.1 \text { (Cashew (BRZ)) [30] } \\
0.28 \text { (Olive oil (Koreniki)) [33] } \\
0.15 \text { (Malaysian virgin coconut oil) [34] }\end{array}$ \\
\hline $\begin{array}{l}\text { Peroxide value } \\
\text { (mEq } \mathrm{O}_{2} / \mathrm{kg} \text { oil) }\end{array}$ & 6.59 & $\begin{array}{l}6.9 \text { (Sesame oil) [35] } \\
\text { <10 (Raw soy bean oil) [17] } \\
1.46 \text { (Virgin olive oil (Barena)) [33] }\end{array}$ \\
\hline Specific gravity $\left(\mathrm{g} / \mathrm{cm}^{3}\right)$ & 0.9167 & $\begin{array}{l}0.9032 \text { (Moringa oleifera seeds oil) [23] } \\
0.9215 \text { (American safflower oil) [17] }\end{array}$ \\
\hline Rancimat (h) & 15.18 & $\begin{array}{l}8.40 \text { (Moringa oleifera seeds oil) [23] } \\
\text { 9-12 (safflower oil) [17] }\end{array}$ \\
\hline Moisture content (\%) & 0.0003 & $\begin{array}{l}2(\text { sunflower seed oil) }[17] \\
0.06(\text { American safflower oil) }[17] \\
\leq 0.2(\text { Extra virgin olive oil) }[32]\end{array}$ \\
\hline \multicolumn{3}{|r|}{ 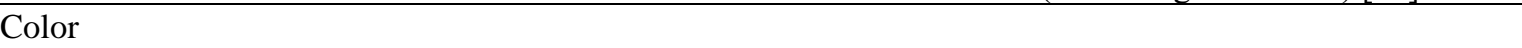 } \\
\hline Red & 2.25 & $\begin{array}{l}1.28 \text { (Moringa oleifera seeds oil) [23] } \\
0.73 \text { (safflower oil (Isfahan)) [31] }\end{array}$ \\
\hline Yellow & -23.33 & $\begin{array}{l}31 \text { (Moringa oleifera seeds oil) [23] } \\
9.8 \text { (safflower oil (Isfahan)) [31] }\end{array}$ \\
\hline \multicolumn{3}{|l|}{ Heavy metals (mg/kg) } \\
\hline $\mathrm{Cu}$ & 0.05 & 1.3 (Sunflower seed oil) [26] \\
\hline $\mathrm{Pb}$ & 0.01 & - \\
\hline $\mathrm{Fe}$ & 0.54 & 4.4 (Sunflower seed oil) [26] \\
\hline As & ND & - \\
\hline
\end{tabular}

*ND= didn't detect. Data are based on mean values of three independent replicates \pm SD.

\subsection{Investigation antioxidant effect of chilgoza pine nut oil on refined rapeseed oil without any antioxidant agent}

After extraction chilgoza pine nut oil by cold pressing method, it was added in two levels (2\% and $5 \%)$ to refined rapeseed oil without antioxidant. The major composition of the fatty acids of rapeseed oil was, respectively, oleic acid $62.85 \%$, linoleic acid $20.25 \%$, linolenic acid $7.71 \%$, palmic acid 5\%, stearic acid $1.68 \%$, arachidic acid $0.56 \%$, erucic acid $0.12 \%$ and meristic acid $0.02 \%$. The samples were stored at ambient temperature and kept away from light. Oxidative stability, peroxide, thiobarbituric acid and Rancimat content of oil samples were determined among 0, 5, 10, 20 and 35 days, and were compared with control samples (free of chilgoza pine nut oil (0\%) and contained of $150 \mathrm{ppm}$ TBHQ antioxidant) (Table 7). This study was done to investigate the effect of both ambient temperatures and accelerated temperature to evaluate the effects of temperature on oil oxidation rate in addition to types and concentrations of antioxidant agents. 
Table 6. Physicochemical composition of chilgoza pine nut oil extracted by cold pressing method compare to other oils

\begin{tabular}{|c|c|c|}
\hline Characteristics & Present oil sample & Other studies \\
\hline \multicolumn{3}{|l|}{ Sterol composition (\%) } \\
\hline \multirow[t]{2}{*}{ Cholesterol } & 0 & 7-13 (Palm oil) [17] \\
\hline & & 0.2 (Moroccan sesame seed oil) [35] \\
\hline \multirow[t]{2}{*}{ Campsterol } & 20.4 & 90-151 (Palm oil) [17] \\
\hline & & 17.8 (Moroccan sesame seed oil) [35] \\
\hline \multirow[t]{2}{*}{ Stigma sterol } & 1.85 & 44-66 (Palm oil) [17] \\
\hline & & 6.4 (Moroccan sesame seed oil) [35] \\
\hline \multirow[t]{2}{*}{ Sitosterol } & 0 & 218-370 (Palm oil) [17] \\
\hline & & 0 (Moroccan sesame seed oil) [35] \\
\hline \multicolumn{3}{|l|}{ Tocopherol (ppm) } \\
\hline \multirow[t]{2}{*}{$\alpha$} & 7.72 & 2.2\% (Sesame seed oil) [35] \\
\hline & & 15.19\% (Pumpkin seeds) [36] \\
\hline \multirow[t]{2}{*}{$\gamma$} & 101.51 & 90.5\% (Sesame seed oil) [35] \\
\hline & & 61.32\% (Pumpkin seeds) [36] \\
\hline \multirow[t]{2}{*}{ Total carotenoid (ppm) } & 1.39 & 81 (Rapeseed oil [37] ( $\beta$ - Carotene)) \\
\hline & & 27.3 (Soy bean oil [37] ( $\beta$ - Carotene)) \\
\hline Total chlorophyll (ppm) & 0.087 & 26.1 (Flax seed oil (Waihi Bush)) [40] \\
\hline \multirow[t]{2}{*}{ Total polyphenol (ppm) } & 168.44 & 0.015 (Pomegranate seed oil) [39] \\
\hline & & 123.82 (Green olive oil) [40] \\
\hline \multirow[t]{2}{*}{ DPPH் (\%) } & 57.5 & 51.8 (Oregano oil) [41] \\
\hline & & 55.3 (Cinnamon oil) [41] \\
\hline \multicolumn{3}{|l|}{ Color } \\
\hline$a^{*}$ & -3.02 & 3.28 (Flax seed oil (MEL)) [38] \\
\hline $\mathrm{L}^{*}$ & 56.28 & 39.63 (Flax seed oil (MEL)) [38] \\
\hline $\mathrm{b}^{*}$ & 49.28 & 08.91 (Flax seed oil (MEL)) [38] \\
\hline
\end{tabular}

*ND= didn't detect. Data are based on mean values of three independent replicates \pm SD.

Table 7. Peroxide, TBA and Rancimat results of soybean oil samples containing of three levels of Chilgoza pine nut oil level

\begin{tabular}{|c|c|c|c|c|c|c|}
\hline & \multirow{2}{*}{$\begin{array}{l}\text { Chilgoza pine } \\
\text { nut oil level }\end{array}$} & \multicolumn{5}{|l|}{ Days } \\
\hline & & 0 & 5 & 10 & 20 & 35 \\
\hline \multicolumn{7}{|c|}{ Peroxide value (mEq $\mathrm{O}_{2} / \mathrm{kg}$ oil) } \\
\hline \multirow{4}{*}{$\begin{array}{l}\text { Chilgoza pine } \\
\text { nut oil }\end{array}$} & $0 \%$ & $2.96 \pm 0.02^{\mathrm{b}}$ & $4.2 \pm 0.1^{\mathrm{c}}$ & $5.77 \pm 0.02^{\mathrm{a}}$ & $9.07 \pm 0.04^{\mathrm{a}}$ & $15.9 \pm 0.04^{\mathrm{b}}$ \\
\hline & $2 \%$ & $3.09 \pm 0.006^{\mathrm{b}}$ & $5.62 \pm 0.003^{\mathrm{a}}$ & $7.56 \pm 0.02^{\mathrm{a}}$ & $10.07 \pm 0.02^{\mathrm{a}}$ & $17.05 \pm 0.02^{\mathrm{a}}$ \\
\hline & $5 \%$ & $3.66 \pm 0.46^{\mathrm{a}}$ & $4.82 \pm 0.03^{b}$ & $7.28 \pm 0.02^{\mathrm{a}}$ & $10.16 \pm 0.02^{\mathrm{a}}$ & $17.58 \pm 0.02^{\mathrm{a}}$ \\
\hline & 150 ppm TBHQ & $2.96 \pm 0.02^{\mathrm{b}}$ & $4.2 \pm 0.1^{\mathrm{c}}$ & $5.77 \pm 0.02^{b}$ & $9.07 \pm 0.04^{\mathrm{b}}$ & $15.9 \pm 0.04^{\mathrm{b}}$ \\
\hline \multicolumn{7}{|c|}{ TBA value (mg MDA/kg) } \\
\hline \multirow{4}{*}{$\begin{array}{l}\text { Chilgoza pine } \\
\text { nut oil }\end{array}$} & $0 \%$ & $0.06 \pm 0.02^{\mathrm{b}}$ & $0.07 \pm 0.1^{b}$ & $0.08 \pm 0.02^{b}$ & $0.09 \pm 0.02^{\mathrm{b}}$ & $0.13 \pm 0.04^{b}$ \\
\hline & $2 \%$ & $0.06 \pm 0.006^{\mathrm{b}}$ & $0.08 \pm 0.003^{\mathrm{a}}$ & $0.09 \pm 0.02^{\mathrm{a}}$ & $0.1 \pm 0.02^{\mathrm{a}}$ & $0.16 \pm 0.02^{\mathrm{a}}$ \\
\hline & $5 \%$ & $0.06 \pm 0.46^{\mathrm{a}}$ & $0.08 \pm 0.03^{\mathrm{a}}$ & $0.09 \pm 0.02^{\mathrm{a}}$ & $0.11 \pm 0.02^{\mathrm{a}}$ & $0.15 \pm 0.02^{\mathrm{a}}$ \\
\hline & 150 ppm TBHQ & $0.03 \pm 0.02^{\mathrm{c}}$ & $0.05 \pm 0.02^{\mathrm{c}}$ & $0.06 \pm 0.02^{\mathrm{c}}$ & $0.08 \pm 0.04^{\mathrm{d}}$ & $0.1 \pm 0.04^{\mathrm{c}}$ \\
\hline \multicolumn{7}{|c|}{ Rancimat result (h) } \\
\hline \multirow{4}{*}{$\begin{array}{l}\text { Chilgoza pine } \\
\text { nut oil }\end{array}$} & $0 \%$ & $16.07 \pm 0.02^{\mathrm{b}}$ & $14.25 \pm 0.1^{\mathrm{b}}$ & $14.23 \pm 0.02^{\mathrm{b}}$ & $12.81 \pm 0.04^{\mathrm{c}}$ & $11.7 \pm 0.04^{\mathrm{b}}$ \\
\hline & $2 \%$ & $16.06 \pm 0.006^{\mathrm{b}}$ & $13.08 \pm 0.003^{c}$ & $12.8 \pm 0.02^{\mathrm{c}}$ & $12.29 \pm 0.02^{\mathrm{c}}$ & $11.23 \pm 0.02^{\mathrm{b}}$ \\
\hline & $5 \%$ & $14.14 \pm 0.46^{\mathrm{c}}$ & $12.86 \pm 0.03^{c}$ & $12.75 \pm 0.02^{\mathrm{c}}$ & $13.6 \pm 0.02^{\mathrm{b}}$ & $10.4 \pm 0.02^{\mathrm{c}}$ \\
\hline & 150 ppm TBHQ & $27.06 \pm 0.02^{\mathrm{a}}$ & $22.36 \pm 0.02^{\mathrm{a}}$ & $22.24 \pm 0.02^{\mathrm{a}}$ & $19.07 \pm 0.04^{\mathrm{a}}$ & $17.8 \pm 0.04^{\mathrm{a}}$ \\
\hline
\end{tabular}

*Considering that the level of significance (or significant probability) is less than 0.0001 , it can be said that there is a significant difference between various treatments at each level $(0.05$ or 0.01$)$.

The peroxide value indicates the amount of initial oxidation products. Based on the results of comparing the amount of peroxide number of refined rapeseed oil without any antioxidant which have been added $150 \mathrm{ppm}$ TBHQ and $0 \%$ (free of chilgoza pine nut oil and antioxidants) as control samples, on days 0, 5, 10, 20 and 35 It can be resulted that chilgoza pine nut oil did not effect on the reduction of rapeseed oil peroxide and initial oxidation products. 
Samples containing 5\% chilgoza pine nut oil had higher TBA values than $2 \%$ and $0 \%$ samples, as well as TBHQ. Therefore, with increasing amount of chilgoza pine nut oil, the production of secondary oxidation products increased. It means that, the chilgoza pine nut oil did not effect on the reduction of secondary oxidation products and the TBA value. One of the main reasons for this resulting is the amounts of PUFA in this oil.

The results showed that over time, oil resistance decreased gradually. The highest rate of resistance was observed in oils containing $2 \%$ and $5 \%$ chilgoza pine nut oil, while the results were significantly different with TBHQ. Generally, the chilgoza pine nut oil did not increase rapeseed oil resistance. Although this test was carried out at ambient temperature, after 20 days, the peroxide value was increased by adding the chilgoza pine nut oil to 10 , which is higher than the maximum permitted for rapeseed oil peroxide. It seems that no antioxidant compounds present in chilgoza pine nut, are not migrated to the oil or is not to a level to completely prevent the oxidation of rapeseed oil and increase its resistance.

\section{Conclusion}

The chilgoza pine nut oil is one of the linoleic oleic acid oil groups; therefore, it is a good source of $\omega 6$ and $\omega 9$ fatty acid groups. The amount of carotenoids and chlorophylls in chilgoza pine nut oil were much lower than other oils (rapeseed, olive, soybeans, etc.). In terms of the amount of tocopherol, this oil contains $\alpha$ and $\gamma$ tocopherol, which is less than other vegetable oils and in this regard, it has fewer antioxidant properties than other reported cultivars. The results showed that in over time, resistance decreased gradually. So that the highest rate of resistance reduction was observed in oils containing $2 \%$ and $5 \%$ chilgoza pine nut oils, while the results were significantly different with TBHQ value and generally the chilgoza pine nut oil did not increase rapeseed oil resistance. It seems that no antioxidant compounds present in chilgoza pine nut, are not migrated to the oil or is not to a level to completely prevent the oxidation of rapeseed oil and increase its resistance.

\section{Acknowledgements}

The authors thank the financial support of Tarbiat Modares University Research Council and instrumental support of Qazvin Standard Organization Specially Dr. Kurosh Rahmani and Sanat Ghazaie Koroush Company.

\section{References}

[1] Cai L, Xiao L, Liu C, Ying T. Functional properties and bioactivities of pine nut (Pinus gerardiana) protein isolates and its enzymatic hydrolysates. Food and Bioprocess Technology. 2013;6(8):2109-2117.

[2] Kumar R, Shamet GS, Mehta H, Alam NM, Tomar JM, Chaturvedi OP, Khajuria N. Influence of gibberellic acid and temperature on seed germination in Chilgoza pine (Pinus gerardiana Wall.). Indian Journal of Plant Physiology. 2014;19(4):363-367.

[3] Malik AR, Shamet GS, Butola JS, Bhat GM, Mir AA, Nabi G. Standardization of seed storage conditions in chilgoza pine (Pinus gerardiana Wall.): an endangered pine of Hind Kush Himalaya. Trees. 2013;27(5):14971501.

[4] Venkatachalam M, Sathe SK. Chemical composition of selected edible nut seeds. Journal of Agricultural and Food Chemistry. 2006;54(13):4705-4714.

[5] Thakur NS, Sharma S, Joshi VK, Thakur KS, Jindal N. Studies on drying, packaging and storage of solar tunnel dried chilgoza nuts. Archives of Applied Science Research. 2012;4(3): 1311-1319.

[6] Cai L, Liu C, Ying T. Changes in quality of low-moisture conditioned pine nut (Pinus gerardiana) under near freezing temperature storage. CyTA-Journal of Food. 2013;11(3):216-222.

[7] Hoon LY, Choo C, Watawana MI, Jayawardena N, Waisundara VY. Evaluation of the total antioxidant capacity and antioxidant compounds of different solvent extracts of Chilgoza pine nuts (Pinus gerardiana). Journal of Functional Foods. 2015;18:1014-1021.

[8] American Oil Chemists' Society (AOCS). Official methods and recommended practices of journal of the American Oil Chemists' Society. Champaign, IL: AOCS Press. 2006.

[9] International Organization for Standardization (ISO 3596). Animal and vegetable fats and oils Determination of unsaponifiable matter -Method using diethyl ether extraction. 2000.

[10] Abedi E, Sahari MA, Barzegar M, Azizi MH. Optimisation of soya bean oil bleaching by ultrasonic processing and investigate the physico-chemical properties of bleached soya bean oil. International Journal of Food Science \& Technology. 2015;50(4):857-863.

[11] Perretti G, Finotti E, Adamuccio S, Della Sera R, Montanari L. Composition of organic and conventionally produced sunflower seed oil. Journal of the American Oil Chemists' Society. 2004;81(12):1119-1123. 
[12] Bhatnagar AS, Prasanth Kumar PK, Hemavathy J, Gopala Krishna AG. Fatty acid composition, oxidative stability, and radical scavenging activity of vegetable oil blends with coconut oil. Journal of the American Oil Chemists' Society. 2009;86(10):991-999.

[13] Carelli AA, Franco IC, Crapiste GH. Effectiveness of added natural antioxidants in sunflower oil. Grasas y Aceites. 2005;56(4):303-310.

[14] Iranian National Standardization Organization (INSO 16324). Olive oil- Determination of the composition and content of sterols and triterpene dialcohols by capillary column gas chromatography- Test method. 2013.

[15] International Organization for Standardization (ISO 9936). Animal and vegetable fats and oils- determination of tocopherol and tocotrienol contents by high-performance liquid chromatography method. 2016.

[16] Ghasemian S, Sahari MA, Barzegar M, Gavlighi HA. Concentration of Omega-3 polyunsaturated fatty acids by polymeric membrane. International Journal of Food Science \& Technology. 2015;50(11):2411-2418.

[17] Hui YH. Bailey's industrial oil and fat products (Vol 4). New York:John Wiley and Sons;1996.

[18] Shad MA, Pervez H, Zafar ZI, Nawaz H, Khan H. Physicochemical properties, fatty acid profile and antioxidant activity of peanut oil. Pakistan Journal of Botany. 2012;44(1):435-440.

[19] Çalışır S, Marakoğlu T, Öğ̈̈ H, Öztürk Ö. Physical properties of rapeseed (Brassica napus oleifera L.). Journal of Food Engineering. 2005;69(1):61-66.

[20] Deshpande SD, Bal S, Ojha TP. Physical properties of soybean. Journal of Agricultural Engineering Research. 1993; 56: 89-98.

[21] Iranian National Standardization Organization (INSO 323). Sesame seed - Specifications and test methods. 2008.

[22] Bedi KL, Atal CK. Study of Indian seed oils. Indian Journal of Applied Chemistry. 1970;33: 181-186.

[23] Anwar F, Rashid U. Physico-chemical characteristics of Moringa oleifera seeds and seed oil from a wild provenance of Pakistan. Pakistan Journal of Botany. 2007;39(5): 1443-1453.

[24] Iranian National Standardization Organization (INSO 2392). Vegetable fats and oils - Soy bean oil Specifications and test methods. 2001.

[25] Iranian National Standardization Organization (INSO 1447). Corn oil - Specifications and test methods. 2010.

[26] Polvillo M, Ruiz GM, Dobarganes MC. Oxidative stability of sunflower oils differing in unsaturation degree during long-term storage at room temperature. Journal of the American Oil Chemists' Society. 2004; 81: 577 582.

[27] Bubonja-Sonje M, Giacometti J, Abram M. Antioxidant and anti-listeria activity of olive oil, cocoa and rosemary extract polyphenols. Food Chemistry. 2011; 127: 1821-1827.

[28] Rossi M, Alamprese C, Ratti S. Tocopherols and tocotrienols as free radical-scavengers in refined vegetable oils and their stability during deep fat frying. Food Chemistry. 2007;102: 812-817.

[29] Mungroo R, Pradhan N, Goud V, Dalai A. Epoxidation of canola oil with hydrogen peroxide catalyzed by acidic ion exchange resin. Journal of the American Oil Chemists' Society. 2008;85: 887-896.

[30] Akinhanmi TF, Atasie VN, Akintokun PO. Chemical composition and physicochemical properties of cashew nut (Anacardium occidentale) oil and cashew nut shell liquid. Journal of Agricultural, Food and Environmental Sciences. 2008;2(1):1-10.

[31] Sahari MA, Morovati N, Barzegar M, Asgari S. Physicochemical and antioxidant characteristics of safflower seed oil. Current Nutrition and Food Science. 2014; 10: 268-274.

[32] Iranian National Standardization Organization (INSO 1446). Olive oil - Specifications and test methods. 2011.

[33] Xiang C, Xu Z, Liu J, Li T, Yang Z, Ding C. Quality, composition, and antioxidant activity of virgin olive oil from introduced varieties at Liangshan. Food Science and Technology. 2017;78: 226-234.

[34] Marina AM, Che Man YB, Nazimah SAH, Amin I. Chemical properties of virgin coconut oil. Journal of the American Oil Chemists' Society. 2009;86: 301-307.

[35] Gharby S, Harhar H, Bouzoubaa Z, Asdadi A, El Yadini A, Charrouf Z. Chemical characterization and oxidative stability of seeds and oil of sesame grown in Morocco. Journal of the Saudi Society of Agricultural Sciences. 2017;16(2):105-111.

[36] Nyama KL, Tan CP, Lai OM, Long K, Che Mana YB. Physicochemical properties and bioactive compounds of selected seed oils. Food Science and Technology. 2009; 42: 1396-1403.

[37] Rafatowski R, Zegarska Z, Kuncewicz A, Borejszo Z. Fatty acid composition, tocopherol and ß-carotene content in Polish commercial vegetable oils. Pakistan Journal of Nutrition. 2008;7(2): 278-282.

[38] Choo WS, Birch J, Dufour JP. Physicochemical and quality characteristics of cold-pressed flaxseed oils. Journal of Food Composition and Analysis. 2007;20: 202-211.

[39] Schubert SY, Lansky EP, Neeman I. Antioxidant and eicosanoid enzyme inhibition properties of pomegranate seed oil and fermented juice flavonoids. Journal of Ethno Pharmacology. 1999;66: 11-17.

[40] Gimeno E, Castellote AI, Lamuela-Raventos RM, De la Torre MC, Lopez-Sabater MC. The effects of harvest and extraction methods on the antioxidant content (phenolics, $\alpha$-tocopherol, and $ß$-carotene) in virgin olive oil. Food Chemistry. 2002;78: 207-211. 
[41] Tomaino A, Cimino F, Zimbalatti V, Venuti V, Sulfaro V, De Pasquale A. Influence of heating on antioxidant activity and the chemical composition of some spice essential oils. Food Chemistry. 2005;89: 549-554.

(C) 2020 by the author(s). This work is licensed under a Creative Commons Attribution 4.0 International License (http://creativecommons.org/licenses/by/4.0/). Authors retain copyright of their work, with first publication rights granted to Tech Reviews Ltd. 